\title{
UMA VISÃO SOCIOCOGNITIVA DA AVALIAÇÃO EM TEXTOS ESCOLARES
}

\author{
Ana Flávia Lopes Magela Gerhardt*
}

\begin{abstract}
RESUMO: Na década de 1980, o educador Percival Brito, discutindo aspectos problemáticos das redaçōes dos alunos nas aulas de língua portuguesa, afirmou que, na relação professor-aluno em sala de aula, a escola se personifica na figura do professor, o que causaria uma despersonalização de ambas as partes. Neste artigo, dedicamo-nos a ampliar o escopo de validação da tese de Brito por meio da sua inserção num arcabouço sociocognitivo de reflexão sobre a linguagem, que define a relação descrita acima como uma mesclagem conceptual. Para tanto, sumarizamos os pressupostos sociocognitivos fundamentais para nosso estudo e descrevemos a mesclagem conceptual existente no fenômeno em questão. Em um estudo de caso, verificamos como a presença da instituição escolar na relação professor-aluno pode definir critérios de "certo-errado" para tarefas escolares.

Palavras-chave: Avaliação. Hipótese sociocognitiva. Mesclagem conceptual. Interação. Ensino de língua portuguesa.
\end{abstract}

\section{A SOCIAL-COGNITIVE VIEW OF ASSESSMENT IN SCHOOL TEXTS}

ABSTRACT: In the eighties, while discussing problematic aspects of students' texts in Portuguese language classes, educator Percival Brito claimed that, in the student-teacher relationship in the classroom, school is personified in the teacher's figure, which would cause a dispersonification of both parts. This paper amplifies the validation scope of this idea by inserting it in a socialcognitive framework about language, which defines the relationship depicted above as a conceptual blending. It thus summarizes the social-cognitive presuppositions basic to our study and

Doutora em Letras e professora da Faculdade de Letras da Universidade Federal do Rio de Janeiro (UFRJ).E-mail: gm@superonda.com.br 
describes the conceptual blending in the phenomenon at issue. In a case study, we verify how the presence of the school institution in the teacher-student relationship can define "right-wrong" judgments for school tasks.

Key words: Assessment. Social-cognitive hypothesis. Conceptual blending. Interaction. Portuguese language teaching.

\section{Introdução}

$\mathcal{E}$

m 1983, o educador Percival Leme Brito publicou o artigo "Em terra de surdos-mudos - um estudo sobre as condiçōes de produção de textos escolares", trazendo provocações importantes num período de efervescência nos estudos em lingüística aplicada ao ensino de língua materna, os quais, em sua maioria, discutiam a produção de textos na escola. Entre algumas afirmaçōes até hoje ainda lembradas, o que de mais impactante foi apresentado pelo autor dizia respeito a um novo escopo, à época, de reflexão sobre os resultados das avaliaçóes oficiais de ensino - sobretudo o vestibular, que implementara havia pouco as provas discursivas e revelara a grande precariedade dos textos dos candidatos: Brito, em seu texto, observou as relaçôes professor-aluno em sala de aula, fortemente marcadas pela institucionalização.

Neste artigo, reencaminhamos as idéias de Brito em direção a uma abordagem sociocognitiva dos problemas identificados pelo autor. Apresentamos subsídios que ampliam o raio de validação da sua tese, que encontra um campo fértil de verificação não apenas para a produção textual, mas também para as atividades escolares em geral, as quais, numa perspectiva sociocognitiva, poderão ser examinadas quanto aos aspectos interacionais em foco na sala de aula, e às expectativas de resultados que permeiam a execução das atividades escolares.

A viabilidade da reconfiguração das idéias de Brito repousa na discussão sobre linguagem e ensino fundada em arcabouços teóricoepistemológicos hoje capazes de considerar os mecanismos cognitivos subjacentes à organização e produção dos significados via linguagem, a par dos padróes comunicativos e da distribuição de papéis de fala entre as pessoas em interação. Quanto a esta proposta, tomamos em conta que a tese de Brito revela uma percepção seminal de que as açôes com a linguagem na escola são permeadas por modelos interacionais; supo- 
mos, por isso, que nossa inserção amadurece e reconhece as idéias daquele autor como um argumento concernente a um fenômeno sistemático, instanciado em diferentes domínios e passível de análise nos seus pormenores.

Para desenvolver esse raciocínio, descreveremos brevemente os pensamentos de Brito interferentes em nossa reflexão, para depois refocalizá-los e ampliar seu escopo numa ótica sociocognitiva, discutindo a avaliação escolar com base em um estudo de caso em que se confronta a resposta esperada para uma determinada tarefa com o que foi efetivamente realizado pelos alunos. Para tanto, selecionamos o teste de leitura aplicado junto a alunos do ensino fundamental e divulgado pelo programa Fantástico, da Rede Globo, ${ }^{1}$ em julho de 2004 . Serão comentados aqui os resultados de uma parte desse teste, aplicada em uma turma de escola pública do município de Barra Mansa, estado do Rio de Janeiro.

\section{A argumentação de Percival Brito}

Em seu artigo, Brito (op. cit.) baseou-se na natureza interlocutiva da linguagem, que supõe o receptor interferindo, como "um agente por tabela”, em todos os eventos de produção de significados lingüísticos; esta relação moldaria, em grande medida, as ações discursivas. E, já que a escrita também pode ser caracterizada como uma prática interlocutiva por excelência, isso permite ao autor identificar este caráter também determinando e fundamentando os objetivos dos alunos ao escreverem seus textos na escola.

Quanto a esse fator, Brito lembra o trabalho de Pécora (1983), que, em princípio, estabelece que o aluno, ao escrever seus textos escolares, escreve para ninguém, isto é, ao elaborar seus textos, não o faz direcionandose para qualquer interlocutor, indefinido que seja. Em seu trabalho, Pécora mostra como o interlocutor ausente pode gerar problemas na estrutura do texto - especificamente, de coesão referencial e seqüencial.

Contrapondo-se ao argumento de Pécora, Brito afirma que as questôes mais problemáticas da produção de textos na escola não se relacionam à ausência de interlocutor para as redações, mas sim à "forte presença de sua imagem", que se configura não como uma imagem pessoal, como a do professor, por exemplo, mas sim como uma imagem institu- 
cional que o professor corporifica, justamente por ser o transmissor de todas as regras de comportamento escolar lingüístico e não-lingüístico. E o aluno, por sua vez, reconhece que, para ter sucesso em seus empreendimentos na sala de aula, deve sobretudo atender aos padrões de avaliação inferidos e reconhecidos na prática do professor.

Além de afirmar que um interlocutor institucional pode regular a escolha das estratégias de coesão textual nas tarefas dos alunos, Brito aponta outras marcas textuais que também justificam sua existência na relação entre o aluno e o sistema escolar metonimizado na figura do professor: hipercorreçōes; uso de palavras "difíceis", estranhas ao universo de alunos jovens e sem hábitos de leitura (revelando um "formalismo aparente"); emprego equivocado do pronome relativo; inversóes sintáticas ("não queria ela", "fácil ficaria"). Segundo Lemos (1977), trata-se de "estratégias de preenchimento", com a função de aproximar a escrita do aluno a um esquema formal de texto que ele supóe ser adequado ao professor-instituição. Brito nota que estas estratégias são exatamente isto conjuntos de formas, e autenticam, para além da pouca familiaridade entre o aluno e o discurso escrito, a redução do processo de construção do texto a uma mera tarefa escolar, incapaz de representar a expressão dos pensamentos e concepções do aluno. Neste sentido, não apenas o professor se despersonaliza na relação institucional que mantém com o aluno este também se dessujeitiza e se minimiza, preocupando-se mais em atender a um sistema de avaliação que infere e incorpora ao longo da sua existência como estudante, do que propriamente em formar-se como pessoa por meio da compreensão plena dos conteúdos e da expressão das suas próprias idéias.

Ao longo dos anos que se seguiram às afirmações de Brito, a literatura dedicada a discutir as relaçôes entre professores e alunos na escola e a sua interferência no processo de ensino em suas práticas mais comezinhas, como perguntar e responder, já tem deixado claro que toda ação neste ambiente está eivada e, muitas vezes, acontece como decorrência de uma série de papéis e posturas tácitas, preestabelecidas e bem conhecidas de ambas as partes (cf., por exemplo, Geraldi, 1991; Souza, 1995). Ao perguntar, o professor o faz alimentando a expectativa de que o aluno elabore apenas uma resposta, que não raro não é a que ele, o professor, supõe ser a certa (quando ele se questiona sobre isso), mas sim a que está no livro didático. Ao responder, o aluno também o faz procurando satisfazer o que ele sabe que esperam dele, não apenas o professor, 
mas todo um sistema representado pelo professor e que será replicado em outros momentos da sua vida escolar, civil e profissional.

No tempo que se seguiu à publicação do artigo de Brito, muitos autores também se dedicaram a perscrutar as interfaces entre as produções do aluno e os aspectos do seu auto-reconhecimento dentro da instituição escolar, a par da imagem e dos deveres que a escola lhe atribui. Tais trabalhos têm-se realizado mediante diversas heurísticas: observação das cenas de sala de aula, avaliação da produção de textos, análise de livros didáticos, abordagem das questôes sobre letramento, discussão dos dados oficiais de aprendizado.

No que tange às feições lingüísticas daquelas produções, diversas angulações teórico-epistemológicas alicerçaram as pesquisas realizadas: a lingüística textual, a sociolingüística, a análise do discurso $(\mathrm{AD})$ e a psicolingüística (cf. Coracini, 1995; Kleiman, 1996; Kato, Moreira \& Tarallo, 1997; Terzi, 1997; Orlandi, 1998; Soares, 2003). Entretanto, as questôes abordadas pelos diferentes estudos eram tratadas de forma estanque: por exemplo, os processos cognitivos descritos pela psicolingüística, a saber, as estratégias cognitivas e metacognitivas de processamento de informação e de aprendizado, não têm sido considerados como diretamente afetados pelas tensões e definiçôes de papéis institucionais em sala de aula, a qual se reconhece como um microcosmo de confrontos sociais mais amplos, relativos às questões de classe, etnia, crenças, faixas etárias etc. Por limitações teóricas das abordagens em psicolingüística, a articulação entre o indivíduo cognitivo e o indivíduo sociointeracional não era tomada plenamente, e os estudos limitavam-se a abordar o jogo entre informação visual e não-visual (esta consistindo em conhecimento de mundo tratado de forma não sistemática).

Por outro lado, e também por limitações teóricas, a análise do discurso não tem se envolvido com o fato de que aspectos socio-históricos de estabelecimento dos papéis e ações destinadas a professores e alunos na escola podem ter contrapartes cognitivas de grande relevância. $\mathrm{O}$ máximo a que se chega é a verificação das marcas lingüísticas das tensões sociointeracionais, o que Brito já havia compilado em seu artigo, de maneira que a $\mathrm{AD}$ não poderia representar um passo adiante das propostas daquele autor.

O que passamos a descrever nas próximas seções diz respeito à possibilidade de abordar sociocognitivamente a produção de significa- 
dos lingüísticos em sala de aula, especificamente na produção de respostas dos alunos para as tarefas escolares que lhes são colocadas.

O aporte sociocognitivo para a produção e o partilhamento de linguagem e conhecimento

Com o advento da hipótese sociocognitiva sobre a linguagem e o pensamento (Salomão 1997, 1999, 2003; Tomasello, 1999; Miranda, 2000; Hutchins, 2002; Gerhardt, 2003), passou-se a observar o fenômeno da cognição humana como um processo efetuado interativamente. As pressuposiçōes geradas no seio desta abordagem ampliam sobremaneira o debate acerca do ensino de língua, articulando-se perfeitamente com a visão de que a produção dos materiais para avaliação escolar será observada com grande fidedignidade se levarmos em conta os fenômenos gerados pela assimetria hierárquica entre o professor e o aluno.

A prescrição sociocognitiva supõe que a mente humana elabora e padroniza universos de experiência enquanto interage com o ambiente externo, e esta capacidade é o pré-requisito essencial para o desenvolvimento da inteligência e a aquisição de novos conhecimentos com base em outros já existentes. Tal proposição favorece enormemente os estudos sobre como as relações sociais interferem na construção da linguagem. É preciso dizer, a propósito, que por "social" aqui estamos entendendo não um universo macroconstituído, lugar das tensões entre as formas de segmentação de grandes grupos sociais, mas sim o que se materializa dessas tensōes nos eventos de interação.

Entretanto, numa ótica sociocognitiva, os contextos de comunicação assumem um estatuto de universos complexos, porque esta abordagem amplia o escopo de observação das pessoas construindo linguagem em interação, fazendo descortinarem-se, na comunicação, as diferentes dimensōes em que seus participantes se constituem como individualidades: uma dimensão filogenética, visualizada no processo evolutivo que o homo sapiens tem operado para alcançar o seu atual estágio de desenvolvimento; uma dimensão social, calculada pelas geraçôes e pelo conhecimento acumulado de que todos somos herdeiros; uma dimensão ontogenética, avaliada no tempo de vida de cada pessoa e no que ela é capaz de transformar com base no que recebe das gerações anteriores (Tomasello, 1999). Saliente-se que essas três dimensões 
se articulam continuamente, isto é, que qualquer transformação ocorrida em cada uma delas necessariamente será percebida e assimilada de alguma forma pela outra.

Este pensamento agrega-se a uma outra disposição sociocognitiva a da não-autonomia entre a linguagem e as outras formas de cognição, com o corolário de que todo universo de experiência, individual ou coletivo, é forma de significação apta a ser redescrita em outra, guardadas as peculiaridades detectadas nesse processo. No tempo ontológico, as pessoas acionam as habilidades de aprendizado da sua espécie - "universaiscognitivas, culturais e sociais-cognitivas” (Tomasello, op. cit., p. 135) para contatar, compreender e manejar os saberes e a língua que suas próprias culturas criaram e alteraram por geraçóes com sua história social.

Um outro conceito sociocognitivo importante para a compreensão da linguagem é o fato de estarmos tratando de representações que assumem um perfil intersubjetivo e perspectival, relativo à negociação de papéis e de significados operada em qualquer ato comunicativo. O perfil intersubjetivo relaciona-se ao fato de que qualquer codificação lingüística é compartilhada na interação, daí podermos afirmar que toda forma de linguagem, para muito além de ser um produto de processamentos de informação, é uma ação conjunta, e é dessa forma que se observará qualquer experiência humana que envolva a linguagem. O perfil perspectival, de sua conta, provém do entendimento da cognição como sendo, acima de tudo, uma event cognition, ou seja, uma cognição gestáltica, e assim não será possível considerar qualquer fato de língua dissociado do meio ambiente em que se produziu, porque assumimos que as formas lingüísticas representam contextos em que interagem entidades e processos. $\mathrm{O}$ reconhecimento desse perfil permite afirmar que toda forma lingüística é um enquadre de cenas visualizáveis na comunicação, no sentido de que a enunciação faz emergir disposições relativas entre os elementos em jogo e marca a importância que se queira conferir a cada informação a que se aludiu na mensagem.

Do que foi dito acima, deve-se acrescentar que, para a constituição de qualquer pesquisa sociocognitiva, é essencial a noção de dominios cognitivos, universos em que estão circunscritas, organizadas e relacionadas, de variadas formas, as experiências humanas. Especificamente, para a análise que faremos, interessam-nos as noções de modelos cognitivos idealizados (MCI), esquema imagético e moldura comunica- 
tiva, formados com base em conhecimentos, conceitos, percepções e experiências altamente organizados. Esses três elementos constitutivos da cognição humana tomam parte importante em hipóteses sobre a natureza das respostas produzidas pelos alunos às atividades pedidas.

Os MCIs são formas de pensamento e opinião produzidas no seio de cada cultura em particular. Esta noção, que conta com o pressuposto de que a cognição é culturalmente motivada, é fruto do amadurecimento dos conceitos relacionados ao chamado conhecimento de mundo, elemento sempre presente nas abordagens psicolingüísticas que postulam o modelo interativo de processamento de informação (Kato, 1985; Kleiman, 1995). Assim, conceitos como família, política, religião, escola etc. são MCIs, porque se definem em nossa mente como padróes culturais aos quais os elementos se encaixam mais ou menos, conforme as características que apresentam.

Os esquemas imagéticos são padrões abstratos originados de percepções gestálticas, gerados por experiências recorrentes que vamos tendo com o espaço à nossa volta e com os objetos dispostos em torno de nós. Trata-se de padrôes que fundamentam construtos espaciais como contenção, limite, proximidade/distância, início/fim etc.

As molduras comunicativas ${ }^{2}$ são entendidas como alinhamentos de informaçōes disponíveis em cada evento cultural, e que o caracterizam: jogos, cerimônias, aulas, brincadeiras etc. se organizam como conjuntos de elementos e ações peculiares organizados de forma altamente hierarquizada, esquematizada. Estes elementos estão atrelados às diferentes práticas sociais que nos são tão necessárias em sociedade, bem como ao uso da linguagem, que é negociado relativamente a cada moldura em que marca presença. As molduras devem ser conhecidas dos participantes de um evento de comunicação, para que eles saibam como devem movimentar-se, portar-se, e também o que podem e não podem expressar, para não correrem riscos de mal-entendidos e constrangimentos.

A noção de moldura decorre do reconhecimento de que toda construção de significado está investida de uma prescrição pública, e por isso deverá depender sempre de negociação entre os interlocutores para atingir sua meta de transmitir informações, convencer, conduzir, persuadir, entre outras tantas ações feitas com a linguagem. É importante notar que as molduras trazem em seu bojo os comportamentos lingüísticos bem como todas as outras formas de comportamento, que 
também produzem significados tão importantes quanto o que se diz, e muitas vezes determinam o que se diz. A forte hierarquização dos elementos em jogo na interação permite que eles sejam identificados com clareza, o que nos faculta avaliar quais aspectos ambientais interferem na construção do significado, e de que forma.

Os aspectos sociocognitivos das interações mediadas pelas tarefas escolares

O amadurecimento das reflexões brevemente descritas acima, a par de outras que aqui não foram citadas, tem produzido variadas frentes interdisciplinares de enquadramento da questão de como o uso da língua contribui para configurar a mente humana, com base no reconhecimento de que a linguagem é uma forma de cognição constituída com a finalidade de promover a comunicação interpessoal. Todas assumem como ponto pacífico (i) a idéia de que processos sociais e culturais participam ativamente do desenvolvimento de habilidades cognitivas individuais e (ii) a proposta de que a complexidade da expressão lingüística provém da necessidade do falante de adaptar os referentes que deseja expor aos ambientes que compartilha com os seus interlocutores no momento da comunicação.

Em estudo clássico sobre os papéis dos participantes na conversação, Goffman (1998 [1979], p. 76) já havia alertado para a insuficiência dos conceitos monolíticos de falante e ouvinte. Para o autor, ao tomar tão-somente o aspecto sonoro como perspectiva, as noções sublinhadas acima não capturam o espaço circundante, cujos elementos interferem na construção dos significados em jogo, nem a disposição e condiçôes de alinhamento dos sujeitos e objetos no espaço, nem outros estímulos humanos presentes e decisivamente atuantes na produção e compreensão de sentidos: o campo visual, os movimentos e a posição do corpo, os gestos das mãos. Esses aspectos articulam-se à voz e suas inflexôes para enriquecer o processo de semiose, que conta continuamente com todas as formas significantes.

A proposta de romper com a relação monolítica falante-ouvinte acarreta uma redefinição do estatuto das interações peculiares ao ambiente escolar (entre os alunos, entre alunos e professores, entre professores e direção), bem como das formas de avaliação de conteúdo. Uma vez que 
enquadram cenas relativas aos significados que veiculam, e também fazem parte efetiva do jogo interacional dentro de sala de aula, todos os materiais produzidos pelos alunos agregam formas e expectativas para o seu comportamento lingüístico e não-lingüístico diante do professor e dos colegas. Por exemplo: o aluno, ao ler um texto em sala de aula, reconhece ter em mãos um material cujo escopo circunscreve-se à sala de aula e que, portanto, suscitará uma determinada tarefa, que ele deve cumprir dentro de alguns padrões de elaboração de respostas, a fim de corresponder à expectativa institucional representada na figura do professor, obtendo assim avaliações positivas, notas altas e aprovação.

É dessa maneira que compreendemos as formas de interação definidas para o contexto escolar, bem como todas as atividades que envolvem os seres humanos em ação conjunta. $\mathrm{O}$ espaço de sala de aula é marcado a priori por definiçôes fechadas dos papéis exercidos por cada um dos seus participantes: as normas de comportamento em aula, embora muitas vezes não sejam claramente explicitadas (ou talvez exatamente por isso), influenciam em alto grau tudo o que se faz dentro da escola, e também gozam de aceitação geral na sociedade. Ao realizar as atividades pedidas, o aluno assumirá mais ou menos essas normas, por isso se pode facilmente hipotetizar que, quando o aluno cumpre tarefas escolares, estar certo ou estar errado em suas respostas de alguma forma diz respeito ao nível de incorporação do seu papel dentro de sala de aula.

A consideração desses fatos abre caminhos para reformularmos a maneira de encarar a ação conjunta aluno-professor: será insuficiente avaliá-la como uma interação entre sujeitos cujas participações têm mesmo valor, sendo simetricamente responsáveis, de um lado, pela tarefa de construir significados franqueados pelas formas lingüísticas e, de outro lado, recuperar estes significados combinando-os a uma série de conhecimentos adquiridos previamente. Agora teremos de reconhecer necessariamente que o relacionamento entre esses sujeitos dentro do ambiente escolar será um guia importante para entendermos os discursos produzidos a partir daí, porque tais elementos são cruciais para definir quem são, em sala de aula, os interlocutores a se relacionar por meio da linguagem em qualquer modalidade.

Refletindo sociocognitivamente sobre o que já se opinou na relação aluno-professor em sala, e no ambiente de expectativas mútuas que aí se insere, podemos ampliar a noção oferecida por Tomasello (1999; 
2003), que identificou em termos sociocognitivos o processo cognitivo humano mais primordial, ${ }^{3}$ que inaugura toda a construção de significado: o reconhecimento do outro como um semelhante, noção atrelada naturalmente à busca das intenções do outro com base na observação de suas ações. Tais percepções vinculam-se dialeticamente à assunção de si mesmo como um ser intencional, o que faz com que o processo cognitivo humano mais primordial seja uma ação sociocognitiva:

Em geral, o argumento é o de que, no esforço de compreender as outras pessoas, as crianças humanas aplicam o que elas já experienciam de si mesmas - e essa experiência de si-mesmo altera-se nas fases iniciais do desenvolvimento, especialmente no que tange ao auto-agenciamento. A hipótese é a de que, uma vez que esta nova experiência de auto-agenciamento emerge, uma nova compreensão dos outros emerge como resultado direto. A abordagem corrente pode então ser pensada como uma versão de um modelo de simulação no qual os indivíduos compreendem as outras pessoas, de alguma forma, por analogia consigo mesmos - já que os outros são "como eu" - de uma forma que eles não fazem, pelo menos não da mesma maneira, com objetos inanimados - já que estes objetos são muito menos "como eu". (Tomasello, 1999, p. 70; tradução nossa)

O reconhecimento dessa dialética levou Miranda ${ }^{4}$ a reconfigurar a visão sobre o chamado processo sociocognitivo humano mais primordial, que em seus termos se constituiria numa integração conceptual em outras palavras, num processo de mesclagem, que consiste numa relação entre elementos de dois diferentes domínios de experiência, chamados domínios input, articulados para formar um terceiro elemento, num domínio que chamamos espaço-mescla, que assume identidade própria, daí seu nome estrutura emergente. Considera-se hoje que a produção de significado por excelência, com base na manipulação de elementos já existentes, se faz por mesclagem, por meio da qual se criam entidades, relações entre entidades e inserçôes destas em novos universos, que não seriam possíveis com os inputs em isolado.

$\mathrm{Na}$ mescla conceptual que ocorre entre os interlocutores em interação, os inputs seriam os sujeitos em interação, e o espaço emergente seria os seus interlocutores, composto de elementos que são parte tanto daquele que elabora uma dada mensagem, quanto daquele que a recebe. A mescla conceptual entre os sujeitos engajados numa comunicação seria assim a ação sociocognitiva mais primordial do ser humano, que fundamenta a sua compressão de significados. 
Esta assunção alicerça toda a hipótese sociocognitiva, porque estabelece de que forma a cognição humana é interativamente sustentada, conforme salientado por Salomão (2003). A autora inspira-se na idéia de Hutchins (2002) de que "um grupo social é um sistema cognitivo com propriedades distintas daquelas apresentadas pelos indivíduos que o compóem”, para reafirmar o processo de mesclagem conceptual na base da formação e do entendimento de uma cena interacional, de forma tal que os participantes do discurso se instituem como espaços input deste processo. Daí resulta uma belíssima esquematização da configuração dos sujeitos interlocutores no exato momento da comunicação em que se constituem efetivamente como tais - serão os espaços emergentes resultantes do processo de mesclagem, conforme transcrito abaixo (Salomão, 2003, p. 81). Este esquema busca em princípio definir o chamado falante no papel de Interlocutor 1' (neste artigo, o aluno), mas salientamos que também o chamado ouvinte (neste artigo, o professor), parte fundamental na constituição dos significados em curso na interação, também emerge como espaço-mescla; sendo assim, este espaço também é instância em que se configura um Interlocutor 2', que foi acrescentado por nós no esquema de Salomão, salientando-se que o interlocutor 1' e o interlocutor 2' são produzidos por processos de mesclagem próprios:

\section{Figura 1}

(mesclagem conceptual dos interlocutores)

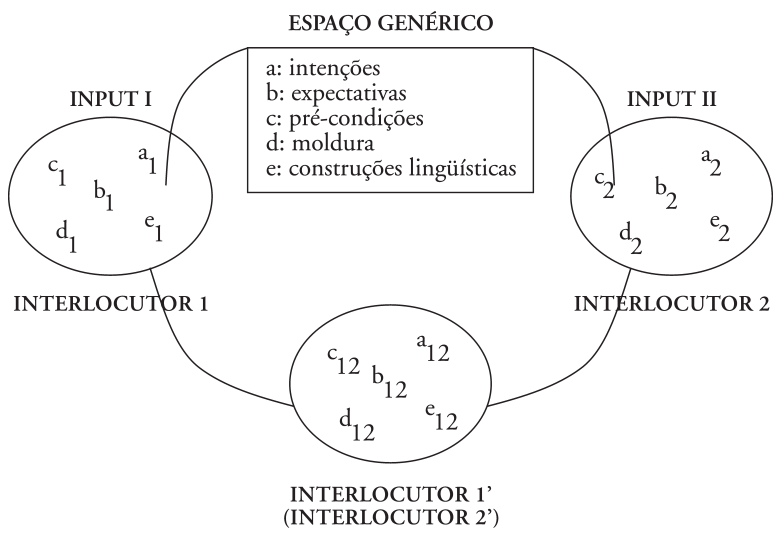

ESPAÇO MESCLA (ESTRUTURA EMERGENTE) NO MOMENTO DA COMUNICAÇÃO 
Refletindo sobre a mesclagem entre os interlocutores que caracteriza toda interação humana, é possível repensar a relação entre os participantes de qualquer forma de discurso, já que, havendo mesclagem entre os egos para a configuração do interlocutor, comunicamo-nos não para um outro, especificamente, mas sim para uma mescla entre o que somos, ou que pensamos ser, e os outros, ou o que pensamos sejam os outros, porque projetamos neles expectativas relacionadas aos resultados de nossa fala. Assim, não vemos as pessoas tais quais são, mas mescladas às expectativas que alimentamos sobre elas, as quais, em última instância, somos nós mesmos, já que estas expectativas são as de que elas se assemelhem a nós, fazendo o que faríamos numa dada situação. A visão sociocognitiva de como se configuram os participantes de uma situação comunicativa vem aprimorar a concepção de Goffman (op. cit., p. 13) de "uma situação social como um ambiente que proporciona possibilidades mútuas de monitoramento": agora podemos supor que este monitoramento se baseia nas mesclagens conceptuais entre os interlocutores, as quais evidentemente diferem de sujeito para sujeito.

É interessante notar que, no caso da relação professor-aluno, marcada por expectativas mútuas, as estruturas emergentes que representam os interlocutores 1' e 2' também se comporão basicamente dessas expectativas. Assim, especificamente na negociação comunicativa em sala de aula, cujos actantes estão ocupando um mesmo espaço e em princípio engajados numa mesma ação conjunta, será esta também uma relação marcada pela mesclagem conceptual, na qual professor e aluno não se comunicam com figuras concretas em si: o aluno, ao comunicar-se, o faz para a estrutura emergente oriunda da mesclagem entre ele mesmo, como input I, e as suas expectativas do que o professor seja, como input II; no caso do professor, este se comunica com a estrutura emergente produto da mesclagem entre ele mesmo, como input I, e suas expectativas de como o aluno deve se comportar, como input II. Essas expectativas, no mais das vezes, são de cunho institucional, quer dizer, referem-se ao que a instituição Escola espera das funções de aluno e de professor, daí a despersonalização/dessujeitização dos que estão dentro de sala, devido à forte carga institucional na constituição dessas figuras, conforme afirmado por Brito (op. cit.).

Dessa forma, amplia-se sobremaneira a compreensão sobre o esvaziamento sofrido tanto pelo aluno quanto pelo professor e denunciado por Percival Brito, podendo-se identificar este processo como um 
fenômeno sociocognitivo que está na raiz das relações entre as pessoas. Entretanto, essa primordialidade da mesclagem como base da interação não é o que deteriora e inviabiliza o encontro entre professor e aluno; para que se resgatem como pessoas pensantes e produtoras de saber em sala de aula, não é necessário que elas passem a elaborar um processo diferente, até porque isso as tornaria menos homo sapiens. O que precisa é serem diferentes os elementos e valores em jogo na mesclagem, isto é, o que estará escolhido e enquadrado no esquema em meio $\mathrm{a} \mathrm{a}_{1}, \mathrm{~b}_{1}, \mathrm{a}_{3}, \mathrm{a}_{4}$ etc., os quais, no estado de coisas descrito por Brito, são justamente os elementos escolhidos na moldura comunicativa aula para compor a "forte imagem do professor", a par da imagem institucionalizada do aluno, como uma pessoa a quem faltam saberes, e não um ser humano que traz saberes que podem transformar a aula.

A forma de diálogo marcada pela mesclagem que seleciona valores institucionais estereotipados subjaz ao padrão que define as respostas "certas" e "erradas" nas tarefas escolares, e que por sinal sobrevive até quando é subvertido, porque seus agentes atuam em circunstâncias claramente definidas. Ao ministrar e corrigir as tarefas escolares, o professor aceita padrões institucionais concretizados na moldura comunicativa aula, provavelmente porque aceita o papel que tem de assumir na instituição escolar, e motiva o aluno a vê-lo assim. O mesmo faz o aluno, que aceita que o professor o veja também pelo viés institucional, porque tem grande interesse em cumprir com o que o levará a uma aprovação ao fim do ano letivo. Portanto, embutida na resposta "certa", estará, travestida muitas vezes de feedback de conteúdo, a satisfação de uma determinada expectativa de comportamento escolar do aluno; de outro lado, inclusa na resposta "errada", estará uma subversão do que é tácita e institucionalmente esperado. Vejamos um exemplo desses fatos:

Fillmore (1983, p. 1) transcreve um dos textos tomados como material de pesquisa para ilustrar como a própria elaboração de alternativas de resposta para a interpretação de um texto conta com açóes previamente definidas para os alunos:

O carpinteiro ficou estarrecido de ver como uma criatura tão estranha e aparentemente frágil como Nasrudin poderia pleitear tal serviço. No entardecer, Nasrudin retornou. "OK, eu lhe darei uma chance", disse finalmente o carpinteiro. "Pegue este machado e corte quanta lenha você puder."

“Quantas árvores você derrubou?”, perguntou o carpinteiro. 
"Toda a lenha da floresta", Nasrudin respondeu.

Chocado, o carpinteiro olhou para fora de sua janela. Não havia nenhuma árvore de pé na colina. Nasrudin havia destruído a floresta inteira.

"Onde você aprendeu a cortar lenha?", perguntou o carpinteiro, estarrecido.

"No deserto do Saara”, respondeu Nasrudin.

"Isso é ridículo!" berrou o carpinteiro. "Não há nenhuma árvore no deserto!"

"Não há AGORA”, disse Nasrudin calmamente. (Tradução nossa) do texto é:

A primeira pergunta feita com o objetivo de avaliar a compreensão

O carpinteiro disse a Nasrudin para

a) procurar por outro serviço

b) cortar quantas árvores pudesse

c) voltar para o deserto do Saara

d) plantar quantas sementes pudesse

O comentário de Fillmore relativo a essa atividade é o de que já existe, prévia e tacitamente estabelecida, a determinação de que não é para os alunos dizerem como a história continua, mas sim para tomála como acabada (mesmo que não haja um fim explícito), e optar por alternativas que representem uma recuperação de fatos arrolados no texto - no caso em questão, a alternativa (b); responder qualquer outra alternativa não será o "certo" a fazer. Ora, é de se notar que optar por qualquer das outras alternativas também é dar uma resposta certa, porque elas também são evidência de que se leu o texto e se criaram expectativas de como ele continua: a literatura psicolingüística sobre o assunto define que a elaboração de expectativas ao longo do processo de leitura é uma estratégia metacognitiva, que a propósito é um dos indicativos de nível de amadurecimento do leitor em pesquisas sobre o tema (Jou \& Sperb, 2003). Assim, o carpinteiro mandar Nasrudin procurar por outro serviço, ou voltar para o deserto do Saara, ou plantar as sementes no terreno já vazio são três conseqüências previsíveis no desenrolar do texto, e bem podem estar na mente do aluno - aliás, de qualquer pessoa - ao fim da leitura do texto. Mas o que lhes confere o estatuto de "erradas", na pergunta escolar, é o fato de que não correspondem ao que se espera do aluno dentro de moldes comportamentais já previstos e antecipados pelos participantes. É bem prová- 
vel, até, que o aluno que respondeu (a), (c) ou (d) conforme-se depois em estar "errado", por já ter internalizado as suas tarefas reais dentro da moldura aula.

Um estudo de caso: a resposta "certa" como checagem de internalização de $\mathrm{MCI}$

Entre as expectativas presentes na moldura aula está a pressuposição de que o aluno já trará internalizados de antemão determinados MCIs que o tornam capaz de oferecer a resposta certa. Isso ocorreu, por exemplo, nos testes de leitura elaborados para a Rede Globo em julho de 2004. Uma das perguntas de interpretação era instanciada pelo texto abaixo:

\section{Lúcia Já Vou Indo}

Lúcia Já-Vou-Indo não sabia andar depressa. De maneira nenhuma. Andava devagar, falava devagar, chorava e ria devagarinho e pensava mais devagar ainda. Muito natural, pois ela era uma lesma.

Um dia, Lúcia recebeu um convite para uma festa. Levou o dia inteirinho para ler o bilhete que dizia assim:

Chispa-Foguinho, a libélula, convida você para uma festa dançante, embaixo do Pé de Maracujá, às oito horas da noite do dia 30 de janeiro. Comes e bebes, muita música, muita alegria, tudo do bom, do melhor e de graça.

Mal acabou de ler, Lúcia já se foi preparando para a festa. Queria se pôr a caminho imediatamente, embora faltasse ainda uma semana.

A pergunta era a seguinte: "Por que a lesma começou a se arrumar assim que acabou de ler o convite?"; e a resposta do gabarito era "Porque ela era uma lesma" - na verdade uma resposta-justificativa circular, porque repete um dos termos da pergunta e, portanto, não traz nenhuma informação nova que esclareça por que Dona Lúcia começou a se arrumar tão incontinenti. Esta circularidade, parece-nos, traz implícita uma expectativa de que, agregado ao nome lesma, esteja o conhecimento por parte do aluno do que é uma lesma, e que a lesma é um animal lento e rastejante, por isso Dona Lúcia Já Vou Indo, uma 
lesma, teria de se arrumar muito cedo para uma festa que só aconteceria dali a uma semana.

Observe-se que a pergunta, respeitada a resposta sugerida pelo gabarito, de forma alguma busca verificar o que seria esperado em um teste de leitura - por exemplo, a capacidade do aluno de pensar sobre a informação do texto relacionando afirmação a justificativa (como sugere o por que), mas sim se ele traz o elemento lesma em seu MCI de animais. Ora, com os dados que o texto oferece, não é necessário saber o que é uma lesma para prover a justificativa que a pergunta pede, porque se salientou mais de uma vez que Dona Lúcia era realmente "devagar". Portanto, os que "erraram" a resposta foram penalizados não por lerem mal, mas sim por não compreenderem que o que se queria deles de fato era que eles soubessem o que era uma lesma. ${ }^{5}$ Mas há uma grande diferença entre saber ler e saber o que é uma lesma...

O teste da Rede Globo foi aplicado em uma turma de quarta série de 22 alunos da Escola Municipal Independência e Luz, em Barra Mansa (RJ). ${ }^{6}$ Transcrevemos abaixo as respostas dadas pelos alunos:

1. Porque ela anda devagar e queria chegar antes da festa começar.

2. Porque ela queria se pôr a caminho imediatamente.

3. Porque ela não queria faltar a festa poricio que ela se arrumou de pressa.

4. Queria se pôr a caminho imediatamente, embora faltasse ainda uma semana.

5. Porque ela andava devagar.

6. Porque se pôr a caminho imediatamente, embora faltasse uma semana.

7. Porque ela era muito lerda por isso ela começou a se a ruma uma semana ante.

8. Por que ela levava dias para chegar lá.

9. Porque se pôs a caminho imediatamente, embora faltasse ainda uma semana.

10. Porque Lucia andava muito devagar

11. Porque queria se por a caminho imediatamente, embora faltasse ainda uma semana. Porque não sabia andar depressa

12. Porque ela era muito devagar em tudo.

13. Porque queria se por a caminho imediatamente.

14. Porque tudo que ela faz e de vagarinho. 
15. Porque ela queria se pôr a caminho imediatamente, embora faltasse ainda uma semana.

16. Porque ela anda muito devagarzinho.

17. Porque ela era uma lesma e pensava devagar, andava devagar e fazia tudo devagar.

18. Porque a lesma é mole, se ela se arrumasse no dia, não ia dar tempo de ela chegar.

19. Ela estava se arrumando para a festa.

20. Porque ela já estava se preparando para a festa.

21. Porque ela ia se atrasar para a festa.

22. Ela foi ser preparando rápido porque ela sabia que não irria chegar a tempo no dia da festa porque sabia que era muito lenta para chegar no dia certo.

Das 22 respostas dadas, apenas as duas últimas não oferecem alguma justificativa válida para o fato de Lúcia Já Vou Indo começar a se arrumar assim que leu o convite. Até as respostas 19 e 20, que focalizam a preparação da personagem e não o fato de ser lenta, também servem como justificativa para a pergunta sobre o motivo de alguém estar se arrumando. Mas apenas as respostas 17 e 18 afirmaram (a 18 indiretamente), além da justificativa, que ela era uma lesma.

As respostas 21 e 22, que apresentam como justificativa o fato de que Dona Lúcia iria se atrasar para a festa, são problemáticas porque evocaram um processo esquemático/lógico diferente dos que estão congruentes com o que foi contado na história: (i) a relação meio-fim (ela se preparou rapidamente para não chegar atrasada na festa) e (ii) afirmação-justificativa (ela se preparou rapidamente porque queria chegar a tempo para a festa); observe-se que ambas as estruturas remetem ao mesmo esquema imagético percurso (Johnson, 1992, p. 28):

\section{Figura 2}

(esquema imagético percurso)

A 
Este esquema subjaz às relações advindas da nossa experiência com a anterioridade e a posterioridade espacial, portanto a todas as relaçóes que envolveriam um começo e um fim, um antes e um depois: meiofim, causa-conseqüência, afirmação-justificativa, premissa-conclusão. Entendemos, com isso, que qualquer resposta vinculada à relação em que antes à Dona Lúcia se arruma para a festa, e, depois à ela quer chegar a tempo para a festa/não quer chegar atrasada, deriva de raciocínio congruente com o texto.

Entretanto, as respostas 21 e 22 afirmam que ela começou a se preparar porque iria chegar atrasada para a festa, o que não nos parece minimamente lógico, à primeira vista. Contudo, já que os alunos afirmaram que, mesmo assim, ela se aprontou para a festa, podemos refletir que as suas respostas inaugurariam um raciocínio hipotético, que não coaduna com as relações do texto: quer dizer, ao afirmarem que Dona Lúcia iria se atrasar para a festa, as respostas podem sugerir que, na hipótese de não se arrumar a tempo, ela chegará atrasada, o que recobre um esquema imagético não suscitado explicitamente pelo texto, embora não de todo incongruente com ele. Este tipo de resposta, numa visão sociocognitiva, suscita reflexões acerca da sua condição de erro, bem como das suas formas possíveis de correção.

Entretanto, a tomar pelo gabarito divulgado pela Rede Globo, estaria "certa" apenas a resposta 17 , que enuncia explicitamente o fato de Dona Lúcia Já Vou Indo ser uma lesma. Portanto, todas as outras teriam respondido a pergunta do teste de forma equivocada.

\section{Retornando às idéias de Percival Brito}

Uma comparação possível entre as evidências apresentadas para os argumentos de Brito, focados na produção de textos, e o nosso estudo de caso, que usa uma tarefa escolar de leitura, revela que ambas as atividades são contrapartes que se direcionam para o mesmo estado de coisas descrito por Brito. O que se tem é, da parte da tarefa escolar, a preparação do aluno despersonificado, por meio de atividades que mostram e educam como ele deve se comportar na escolha das suas respostas para atender às expectativas da escola, premiando como "certos" os que foram bem-sucedidos no teste. Os textos que os alunos produzem apresentam o seu feedback, ou seja, a checagem desta estratégia, já que 
evidenciam o seu nível de internalização das expectativas esperadas. Neste sentido, o texto é o resultado do processo, e a tarefa é a forma de ação, por parte da escola, para chegar a esse resultado, o qual, se na aparência se destina a mensurar algum nível de aprendizado dos alunos, na realidade denuncia o seu nível de despersonalização, por eles terem aprendido, durante a feitura das tarefas e avaliaçôes, a selecionar, entre os elementos que usarão para elaborar a mesclagem de interlocutores necessária à interação com seu professor, justamente aqueles relativos às expectativas institucionais.

Assim, podemos afirmar que o nosso estudo de caso, pensado à luz da delimitação sociocognitiva do espaço interacional de sala de aula, com uma definição de como agem os seus indivíduos participantes, já traz subsídios suficientes para que possamos ratificar e aprofundar os argumentos que motivaram este artigo, os quais articulam a qualidade dos textos produzidos pelos alunos à forma da relação entre eles e seus professores, na qual se opera uma dessujeitização de ambas as partes, em prol da inserção das normas de comportamento definidas pela instituição escolar. Uma vez que amadurecemos a tese de Brito em bases sociocognitivas, disponibilizamos reflexões para a avaliação escolar, a qual pode estar vinculada a molduras comunicativas e determinadas regras de conduta que ultrapassam os limites do relacionamento professor-aluno e podem interferir na condução e construção de processos cognitivos. Isso nos leva a questionar as condições de validação dos tipos de tarefas e avaliações escolares, e o que elas realmente estão avaliando - se a aquisição de informações ou a adaptação a um esquema cuja assimilação acarreta notas altas e aprovação no fim do ano.

Nesse questionamento, com base no que temos dito, é possível supor que as noçôes de "certo" e "errado" podem estar intimamente vinculadas a concepçóes escolares muito menos comprometidas com a aquisição e manipulação de informação do que com a internalização de certos saberes sociais. Em outras palavras, se o aluno sabe o que a escola espera que ele saiba e não se ele consegue relacionar e expressar conceitos. E, quanto a isso, podemos também conjeturar em que medida esses saberes são justamente os relacionados a uma elite sociocultural, e autorizados pela escola.

Ao cabo dessas considerações, concluímos pela possibilidade de revitalizar, agora sob uma angulação sociocognitiva, idéias como as de Percival Brito, desenvolvidas há mais de vinte anos. Em contrapartida, 
concluímos, também, lamentavelmente, pela continuidade, no Brasil, do projeto institucional que Brito denunciou e que se mantém estável, malgrado todos os planos nacionais de educação e todos os indicativos oficiais de que o ensino vai de mal a pior. Refletindo sobre essa nefasta estabilidade, não é difícil constatar que as soluções propostas para os problemas verificados olham reiteradamente para o lado errado: a instituição, ao avaliar, nunca se direciona para si mesma e seus valores, mantendo-se teimosamente a olhar o aluno como uma pessoa a quem faltam os saberes autorizados por uma elite. Deveria, portanto, começar pelo que de fato importa, que é exatamente uma reavaliação da escola como espaço que reproduz um estado de coisas mais amplo na sociedade, e uma revisão do que se quer daqueles que estão sob sua responsabilidade. $\mathrm{O}$ olhar voltado para a escola talvez possa ser um início de solução.

\section{Recebido em fevereiro de 2006 e aprovado em abril de 2006.}

\section{Notas}

1. Disponibilizado em <http://fantastico.globo.com/Fantastico/0,19125,TFA0-2142-5907$154919,00 . \mathrm{html}>$.

2. Esta noção é originária dos estudos de Gregory Bateson, que a denominou enquadre (frame). Aqui manteremos o termo moldura comunicativa, adotado pela literatura sobre o assunto no Brasil (Salomão, 1997).

3. Que, aliás, o define fundamentalmente como Homo sapiens e o diferencia dos outros primatas e demais espécies animais.

4. Professora Neusa Salim Miranda, da Universidade Federal de Juiz de Fora (UfJF), em palestra conferida no minicurso "Introdução à Lingüística Cognitiva", em março de 2003, no III Congresso Internacional da ABRALIN, na UFRJ.

5. No site do Fantástico não há percentual de acertos de cada pergunta, apenas um índice bastante geral: $28,1 \%$ dos alunos "erraram" mais da metade da prova.

6. Agradecemos ao professor Alexandre Batista, da Rede Municipal de Ensino de Barra Mansa (RJ), pela aplicação do teste.

\section{Referências bibliográficas}

BRITO, P.L. Em terra de surdos-mudos (um estudo sobre as condições de produção de textos escolares). Trabalhos em Lingüistica Aplicada, Campinas, n. 2, p. 149-167, 1983.

CORACINI, M.J. (Ed.). O jogo discursivo na aula de leitura: língua materna e língua estrangeira. Campinas: Pontes, 1995. 
FILLMORE, C. Ideal readers and real readers. Berkeley: University of California, 1983.

GERALDI, J.W. Portos de passagem. São Paulo: Martins Fontes, 1991.

GERHARDT, A.F.L.M. Teorias e conceitos em lingüística cognitiva: (in)compreensões. Cadernos de Estudos Lingüisticos, Campinas, n. 45, p. 21-31, 2003.

GOFFMAN, E. A situação negligenciada. In: Ribeiro, B.T.; Garcez, P.M. (Ed.). Sociolingüistica interacional: antropologia, lingüística e sociologia em análise do discurso. Porto Alegre: Age, 1998.

HUTCHINS, E. Material anchors for conceptual blends. San Diego: University of California, 2002. Disponível em: <http://hci.ucsd.edu/ lab/publications.htm>.

JOHNSON, M. The body in the mind: the bodily basis of meaning, imagination and reason. Chicago: University Press, 1992.

JOU, G.I.; SPERB, T.M. Leitura compreensiva: um estudo de caso. Linguagem \& Ensino, Pelotas, v. 6, n. 2, p. 6-15, 2003.

KATO, M.A. O aprendizado da leitura. São Paulo: Martins Fontes, 1985.

KATO, M.; MOREIRA, N.; TARALLO, F. Estudos em alfabetização: retrospectivas nas áreas da psico e da sociolingüística. Campinas: Pontes; Juiz de Fora: EDUfJF, 1997.

KLEIMAN, A. Texto e leitor: aspectos cognitivos da leitura. Campinas: Pontes, 1995.

KLEIMAN, A. Leitura: ensino e pesquisa. 2. ed. Campinas: Pontes, 1996.

LEMOS, C. Algumas estratégias. Cadernos de Pesquisa, São Paulo, n. 23, p. 61-71, dez. 1977.

MIRANDA, N.S. A configuração das arenas comunicativas no discurso institucional: professores versus professores. 2000. Tese (Doutorado em Educação) - Faculdade de Educação, Universidade Federal de Minas Gerais, Belo Horizonte. 
ORLANDI, E.P. (Ed.). A leitura e os leitores. Campinas: Pontes, 1998. PÉCORA, A. Problemas de redação. São Paulo: Martins Fontes, 1983. POSSENTI, S. Sobre discurso e texto: imagem e/de constituição. In: Possenti, S. Sobre a estrutura do discurso. Campinas: UnICAMP, 1981.

SALOMÃO, M.M.M. Gramática e interação: o enquadre programático da hipótese sócio-cognitiva sobre a linguagem. Veredas: Revista de Estudos Lingüísticos, Juiz de Fora, v. 1, n. 1, p. 23-39, 1977.

SALOMÃO, M.M.M. A questão da construção do sentido e a agenda dos estudos da linguagem. Veredas: Revista de Estudos Lingüísticos, Juiz de Fora, v. 3, n. 1, p. 61-79, 1999.

SALOMÃO, M.M.M. Razão, realismo e verdade: o que nos ensina o estudo sócio-cognitivo da referência. Cadernos de Estudos Lingüísticos, Campinas, n. 44, p. 71-84, 2003.

SOUZA, L.M.T.M. O conflito de vozes na sala de aula. In: CorACINI, M.J. (Ed.). O jogo discursivo na aula de leitura: língua materna e língua estrangeira. Campinas: Pontes, 1995.

TERZI, S.B. A construção da leitura. 2. ed. Campinas: Pontes; UniCAmP, 1997.

TOMASELLO, M. The cultural origins of human cognition. Cambridge, Mass.: Harvard University, 1999.

TOMASELLO, M. Constructing a language: a usage-based theory of language acquisition. Cambridge, Mass.: Harvard University, 2003. 